By the end of the meeting, both could perhaps agree that their points had been met; there seems to be a general consensus that the Earth is at the start of a potential cooling period of perhaps 10,000 to 20,000 years, possibly not an ice age in the sense of those recorded in geological time, but still a major, long-term change.

At the same time, there was no doubt of the feeling of the meeting as a whole, regarding the possible combined effects of $\mathrm{CO}_{2}$ emissions and those of other pollutants such as nitrous oxide and many chlorine compounds, including the already notorious chlorofluoromethanes. How little is known about the real effects of all these substances is evident from a note in the report of the working group concerned, that "it is possible that some processes could lead to a cooling" (rather than a warming as with $\mathrm{CO}_{2}$ ) "of the atmosphere".

Despite this uncertainty, Ralph d'Arge of the University of Wyoming offered estimates of the economic costs of climatic change. Giving sets of figures for a drop of $1^{\circ} \mathrm{C}$, he calculated that losses in rice production could only be offset by an investment of $\$ 19$ billion-and rice is the staple crop of the majority of the world's poorest people.

Yet perhaps even more significant, as indicating the knife-edge of climate on which many national economies are balanced, are his figures for softwood production in USSR: a drop of $1{ }^{\circ} \mathrm{C}$ would require an offsetting investment of $\$ 28$ billion, whereas only a half degree rise would give a $\$ 13$ billion bonus.

Where urban wages are concerned, this differential is even more marked: for the United States alone, d'Arge's figures jump from a loss of $\$ 73$ billion to a rise of $\$ 31$ billion. So it is not surprising that another conclusion of the conference was that planners, in the industrialised countries as well as those of the Third World, should take climatologists far more into their confidence than they do at present.

Not irrelevant in this connection was a response made to B. J. Mason, Director of Britain's Meteorological Office, when he remarked that variability such as the hot dry summer of 1976 need not be so disastrous: whereas certain British crops did badly, others so improved that the total loss was slight. It was the sole Iranian at the meeting who pointed out that perhaps this was because many crops grown in Britain are at the limit of their natural range, and need a warm summer to be really profitable.

Fascinating data on medium term climatic variation was put forward in the Chinese paper, based on studies of fluctuations over much of the last 5,000 years. Mean temperatures are believed to have varied over a range of two to three degrees -as great as that foreseen under a prolonged "greenhouse effect" today. At the same time, Chinese scientists studying more recent records believe they have identified a number of short-term cycles of from two or three to $11,22,36$ and 80 years for various parameters in different parts of their vast country with, it is admitted, an extraordinarily wide range of normal variation.

Inevitably, a good deal of attention was paid to the use of computers as the main tools in forecasting, especially perhaps over longer ranges of time, although it was agreed that there is an urgent need for better models to work to. Moreover, although no one was so crude as to point this out, an industrialised country such as Britain may well spend as much on a single giant computer as many, if not most, Third World countries have for their entire annual budget in meteorological services.

This point, at least, was reflected in the final Declaration of the Conference, with a call for assistance to these countries through training and the transfer of appropriate technologies without which they cannot participate fully in the proposed World Climate Programme. This programme, a bare outline of which was appended to the Conference Declaration, will be discussed by the WMO Congress when it meets from 30 April for four weeks, with a view to reaching decisions about content and funding.

Peter Collins

\title{
Call for world (non-nuclear) energy organisation
}

THE potential dangers of the rapid growth of nuclear energy on an international scale are so great that there is an urgent need to establish a global body to co-ordinate and stimulate the development of non-nuclear sources of energy, according to Dr Joseph Rotblat, emeritus professor of physics at the University of London, and a leading member of the Pugwash organisation.

Speaking at a meeting in London last week organised by the environment division of the Instiute of Biology, Professor Rotblat said that although a global energy body already existed in the International Atomic Energy Authority, it existed to promote one form of energy-nuclear. No similar body existed to encourage other energy forms. "It is high time that the balance was restored", he said.

A large expansion of nuclear power would greatly increase the chance of nuclear war, said Professor Rotblat, since almost every nation would have access to plutonium, and would also have the technology necessary to make nuclear weapons. "In the long run nuclear energy is not compatible with the survival of civilisation", he said.

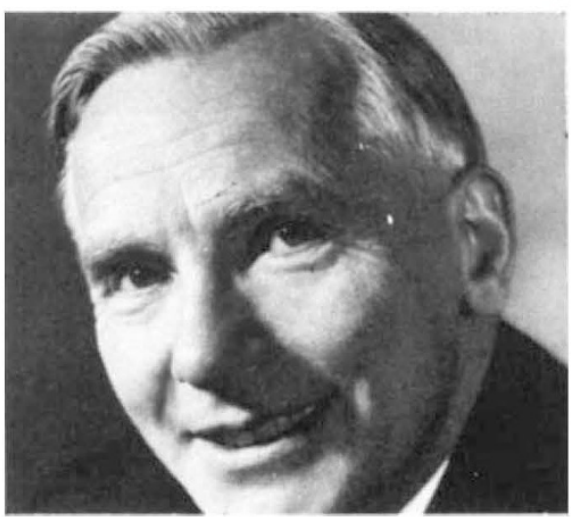

"The most positive thing we could do to reduce the risk of nuclear war would be to encourage countries to opt for non-nuclear sources of energy. A global organisation devoted to this end would be important to give the same aura of respectability to nonnuclear energy sources as is at present given to nuclear energy", Professor Rotblat said.

Professor F. W. Spiers of the University of Leeds told the meeting that measuring background levels of radiation provided an important yardstick for studying the health effects of society's nuclear activities. Whether background radiation was a source of cancer was an open question, he said. "Although we would not anticipate it to have much effect when there are so many other causes of disease".

Levels of background radiation also provided a lower limit for the 'doubling dose' for different cancers, since if this dose was estimated at less than the background level, it would imply that the background radiation was responsible for more than the observed incidence of cancer.

David Dickson 